\title{
The Portfolio Selection Model of Oil/Gas Projects Based on Real Option Theory
}

\author{
Zefu Lin ${ }^{1}$ and Jianyue $\mathrm{Ji}^{2}$ \\ ${ }^{1}$ School of Management Science and Engineering, Central University of Finance \\ and Economics, Beijing 100081, China \\ ${ }^{2}$ School of Economics, Ocean University of China, Qingdao 266071, China \\ linzf@cufe.edu.cn, jjx@ouc.edu.cn
}

\begin{abstract}
Portfolio selection of oil/ gas projects is a fundamental subject of capital budgeting in the energy sector. In industry, strategic planning requires the selection of a portfolio of projects to advance the corporate goals. The term portfolio selection is more devoted to a set of financial assets that are easily traded and divisible. The principles and fundaments of portfolio selection can be used to compare strategies of investments, so that firms get maximum returns. In this paper, we discuss the oil/gas projects valuation methods first. Considering the characteristic of the oil/gas project, Real options method is more suitable for the oil/gas project than NPV method, and then a new model extended from the Black-Scholes model is built up. Finally, this paper put forward the portfolio selection model and gives a Computational case.
\end{abstract}

Keywords: Portfolio selection; Oil/gas projects; Real options theory.

\section{Introduction}

The decisions of committing limited resources to multiple uses can either strengthen or deteriorate their very financial foundation. On one end of the spectrum, capital budgeting procedures often employ traditional operations research (OR) techniques to guide and support decisions. On the other end, executives admit that selections come down to intuition. Typically, however, what is common is to build models that employ pro-forma plans centering on measures of the benefits of the investments returns and risk.

Energy plays an important role in the global economy and politics. The decision about oil/ gas projects is also important for the industry and government. Developing an oil and/or gas field nowadays is subject to considerably larger investments in time, money, and technology. Furthermore, such large investments are almost always based on imperfect, scant, and uncertain information.

Extraction of oil (and/or gas) from a virgin field is undertaken in typically four stages: exploration and appraisal; development; production; and abandonment. This is a gross simplification, of course, for within each phase there are a multitude of technical, commercial, and operational considerations for the management to take optional action. Keeping one eye on real options, in their crudest form these phases can be briefly described as follows: 
Exploration and Appraisal: Seismic data is obtained and a picture of the subsurface is then revealed. Coupled with geological knowledge, experience, and observations it is then possible to generate a more detailed depiction of a possible hydrocarbonbearing zone. Seismic data cannot tell what fluids are present in the rock, so an exploratory well needs to be drilled to better establish the nature, size, and type of an oil and gas field.

Development: Once sufficient data has been obtained (from seismic or exploratory wells) to make an educated judgment on the size of the prize, we enter into the development phase. Here we decide upon the most commercially viable way for exploiting this new resource by engineering the number (and type) of producing wells, process facilities, and transportation. We must also establish if, at all, any pressure support is necessary.

Production: Depending on the size of the reserve, the engineer must manage this resource as carefully as any other valuable asset. Reservoir management (the manner and strategy in which we produce from a field) has become increasingly important over the past few years. Increasing the efficiency of our production from our reservoirs is now a crucial part of any engineering effort.

Abandonment: Once reserves have been depleted, the infrastructure can either be left to decay or - increasingly - it must be dismantled in an environmentally and economically efficient manner.

Portfolio selection of oil/ gas projects is a fundamental subject of capital budgeting in the energy sector. In industry, strategic planning requires the selection of a portfolio of projects to advance the corporate goals. The theory of financial portfolio is well developed and popular with the Markowitz' portfolio theory, which is based in the mean-variance optimization approach (Markowitz, 1959) .This theory, has tentatively been extended to real projects portfolio case, mainly in professional literature. However, although there are good papers showing that diversification principles remain valid (e.g., see Ball Jr. \& Savage, 1999), the real projects case demands a richer portfolio theory in order to capture issues like synergy between real projects and the real options embedded into real projects such as the option to defer and learning options.

There are many challenges in implementing oil/gas portfolios. In particular, the risk and return of individual projects within the portfolio must be characterized in a consistent manner in order to achieve a minimum-risk and a maximum-return. Clearly, it is important to use economic evaluation techniques to characterize these risks and impacts on company performance and long-term value. Traditional methods based upon discounted cash flow (DCF) reported in the finance literature are always based upon static assumptions - no mention about the value of embodied managerial options.

For the case of mutually exclusive projects as those to develop oil and gas reserves, DCF rule tends to favor those with higher NPV values. However, in practice many managers overrule passive net present value (NPV) analysis by using intuition and executive judgment to take future managerial flexibility into assets values (Trigeorgis, 1996. There has been a move to use stochastic or dynamic methods in economic evaluations and portfolio management due to work of several researchers. Luehrman, 
(1994), Copeland (1990) among others, suggest the use of option-based techniques to value implicit managerial flexibility in investment opportunities.

The valuation of projects and business opportunities using DCF and real option theory (ROT) is based on cost-benefit analysis, but they are different in the treatment of risk. Risk is the possibility of loss or gains since future values are dispersed around expected mean values so that the only way to measure risk is using probabilistic approach. Mathematical models for option valuation were firstly developed to price those on common stocks, exchange and interest rates, among others and later migrated to value real options on real assets from industrial projects. Volatility is not preset in DCF, but plays a remarkable role in option pricing.

Option theory methods for oil/ gas projects in the literature seem preoccupied with concern about the affect of future, uncertain oil and gas prices and, less so, on the non-financial options involved. Paddock, J., Siegel, D. and Smith, J. (1988) examine the options arising as better information through time reduces uncertainties in the exploitation of development assets. Luehrman, (1994) delves into the cost of foreclosing the option to develop an oil and gas asset; Lohrenz (1991) does so with respect to shut-in and abandonment of assets.

Obviously, oil/ gas projects give rise to different net cash flows. Each net cash flow has its own uncertainties and the market reacts to the perceived uncertainties. Jacoby and Margrabe (1978) give an option theory valuation methodology that considers each of the cost, net revenue, and tax cash flows and their unique uncertainties. The claimed advantage for their methodology is the ability to define the different risks associated through time for the investor and the taxing government.

\section{Real Option Methods for Oil/Gas Project Valuation}

Real options rest upon an analogy between real option value levers and financial option value levers. Luehrman (1994) established a mapping between project characteristics and financial option value drivers as depicted in table 1.

Table 1. Mapping between real option and financial option

\begin{tabular}{|l|c|c|}
\hline Financial option Value & Variable & Real options Value \\
\hline Exercise price & $\mathrm{X}$ & Investment cost \\
\hline Stock price & $\mathrm{A}$ & $\begin{array}{c}\text { Present value of expected } \\
\text { cash flows }\end{array}$ \\
\hline Time to expiry & $\mathrm{T}$ & \begin{tabular}{c} 
Time to expiry \\
\hline Risk-free interest rate
\end{tabular} \\
\hline $\begin{array}{c}\text { Uncertainty of stock price } \\
\text { movements }\end{array}$ & $\sigma$ & $\begin{array}{c}\text { Volatility of expected cash } \\
\text { flows }\end{array}$ \\
\hline
\end{tabular}


The investment cost is equivalent to the exercise price (X). When keeping the other real options levers constant, an increase in $\mathrm{X}$ will decrease the value of the project as $\mathrm{X}$ represents a negative cash flow.

The present value of the expected cash flows is analogous to the stock price (A). The higher the stock price the higher the value of the option. As a result, an increase in the present value of the expected cash flows will increase the overall value of the project.

The time to expiry is analogous to the time to maturity of a financial option (T). It is the maximum time period - expressed in years - which an investment can be deferred without losing the option to investment in the project. In an uncertain environment, the more time there is to learn about the uncertainty then the more insight will be gained of how to appropriately address the uncertainty. As a result, a longer time to expiry will increase the value of the project.

The risk-free rate $\left(r_{f}\right)$ will increase (decrease) the value of a call (put) option because it will reduce the present value of the stock price (A). It will have the same effect when applied to a real options situation.

The volatility of expected cash flows $(\sigma)$ is analogous to the volatility of stock price movements. Thus, a higher volatility will increase the value of the option.

Two fundamental methods for pricing financial options are the binomial tree model and the Black-Scholes model. In addition to the two models, and Margrabe (1978) put forward the pricing model which be used in exchange option pricing. These optionpricing models also can be used in the oil/gas projects. In the standard binomial tree model (Cox J., S. Ross and M. Rubinstein, 1979), Let C is the value of call option

Let $\mathrm{A}$ follow the binomial distribution, Starting at $\mathrm{t}_{0}$, in one time period $\Delta \mathrm{t}, \mathrm{V}$ may rise to $\mathrm{uV}$ with probability $\mathrm{q}$ or fall to $\mathrm{dV}$ with probability $1-\mathrm{q}$, where $\mathrm{d}<1, \mathrm{u}>1$ and $\mathrm{d}<\mathrm{r}<\mathrm{u}$, with $\mathrm{r}$ being $1+r_{f}$.

So in the binomial tree model, under the assumption of risk-neutral, we can get:

$$
\begin{aligned}
p & \equiv \frac{r_{f}-d}{u-d}, u=e^{\sigma \sqrt{\Delta t}}, d=e^{-\sigma \sqrt{\Delta t}} \\
C=\frac{p C_{u}+(1-p) C_{d}}{1+r_{f}} & =\frac{p \operatorname{Max}(0, u A-X)+(1-p) \operatorname{Max}(0, d A-X)}{1+r_{f}} .
\end{aligned}
$$

This is the binomial tree pricing model of European call options that also can be used in oil/gas project valuation.

\section{The Portfolio Selection Model Based on Real Option Theory}

Based on characteristic of oil/gas project, we can extend the Black-Scholes (1973) as follows according to the previous research (Bjerksund \& Stensland, 1993). The Variables in the model are listed in Table 2. 
Table 2. Variables in the model

\begin{tabular}{|c|c|}
\hline F: Unit value of non-developed reserve; & I: Unit Investment cost; \\
\hline П: Unit profit & B: amount of developed reserve; \\
\hline$\sigma:$ Volatility of V (\% per year) & T: total maturity period (years) \\
\hline$\delta$ : Cash flow or "dividend yield" (\%) & $\begin{array}{l}\text { R: rate of return from developed } \\
\text { reserves; }\end{array}$ \\
\hline $\begin{array}{c}\text { V: Unit value of developed reserve or } \\
\text { underlying asset; }\end{array}$ & $\begin{array}{l}\omega: \text { Yearly production of the global } \\
\text { reserve }(\%)\end{array}$ \\
\hline $\begin{array}{l}\tau: \text { real risk free interest rate after tax (\% per } \\
\text { year) }\end{array}$ & $\begin{array}{c}\tau: \text { Time interval to expire the lease } \\
\text { rights; }\end{array}$ \\
\hline $\begin{array}{c}\mu: \text { Risk-adjusted discount rate or expected } \\
\text { rate of return from V (\%) }\end{array}$ & $\begin{array}{c}\text { dz: Wiener's increment to add } \\
\text { uncertain to the process; }\end{array}$ \\
\hline
\end{tabular}

The model assumes that production evolves over time as exponential decline curve as:

$$
\mathrm{dB}=-\omega_{\mathrm{B}} \mathrm{dt}
$$

Here, $\mathrm{B}$ is the amount of oil and $\omega$ a fraction of the remained global reserve produced every year until economic depletion.

Then we can get the general for option valuation and similar to Black-Scholes equation.

$$
\frac{1}{2} \sigma^{2} V^{2} \frac{\partial^{2} F(V, t)}{\partial V^{2}}+(r-\delta) \frac{\partial F(V, t)}{\partial V}+r \frac{\partial F(V, t)}{\partial t}-r F=0
$$

Considering the economic meaning, we can set certain boundary conditions for the equation. Then we can get the possible approximate solution for the Eq.(4) under certain boundary conditions is given by Bjerksund \& Stensland (1993):

$$
V^{*}=B_{0}+\left(B_{\infty}-B_{0}\right)\left(1-e^{h(T)}\right)
$$

Where:

$$
\begin{gathered}
\beta=\frac{1}{2}-\frac{(r-\delta)}{\sigma^{2}}+\sqrt{\left[\frac{(r-\delta)}{\sigma^{2}}-\frac{1}{2}\right]^{2}+\frac{2 r}{\sigma^{2}}} \\
B_{\infty}=\frac{\beta}{\beta-1} \\
B_{0}=\max \left[I,\left(\frac{r}{r-\delta}\right) I\right] \\
h(T)=-((\rho-\delta) T+2 \sigma \sqrt{T}) *\left(\frac{B_{0}}{B_{\infty}-B_{0}}\right) .
\end{gathered}
$$


When the firm exercises the option to develop the reserve, there is a exchange between investment and reserve value that may take place now or in the future. Then, a general expression for option valuation is of the form:

In a general case when the firm has $\mathrm{n}$ projects, the portfolio selection problem reduces to Maximize portfolio's NPV as:

$$
\begin{aligned}
& \operatorname{Max} \sum_{j=1}^{n} N P V_{j} x_{j} \\
& \text { S.t. } \sum_{j=1}^{n} I_{j} x_{j} \leq I^{*} . \\
& x_{j}=0 \text { or } 1
\end{aligned}
$$

Zero-one programming is better than the other portfolio selection methods such as index ranking etc. since it allows optimization of the full budget together with maximum NPV or other DCF's indicator. Considering the real option included in the petroleum projects, the portfolio selection model should reconsider the optimization objective as followed:

$$
\begin{aligned}
& \operatorname{Max} \sum_{j=1}^{N} V_{j}^{*} x_{j} \\
& \text { S.t. } \sum_{j=1}^{n} I_{j} x_{j} \leq I^{*} . \\
& x_{j}=0 \text { or } 1
\end{aligned}
$$

\section{Computational Case}

Firm L has 4 oil/gas projects to develop proved reserves under a constrained budget of US\$ 600 million. Table 3 shows the geological and financial aspects of all potential reserves. These reserves present little proportionality among many variables, especially in correlation to reserve's size.

Table 3. Data of the potential projects

\begin{tabular}{|c|c|c|c|c|}
\hline Projects & A & B & C & D \\
\hline Price (US\$) & 54 & 54 & 54 & 54 \\
\hline B (MMbbl) & 500 & 600 & 850 & 620 \\
\hline$\delta(\%)$ & $2 \%$ & $1.5 \%$ & $1.2 \%$ & $2 \%$ \\
\hline T(year) & 25 & 19 & 22 & 15 \\
\hline Investment (MM US\$) & 150 & 240 & 180 & 250 \\
\hline
\end{tabular}


Considering that all projects present similar geological characteristics and comparable risk features, managers may be tempted to select project A, B, C according to the original decision model based on the NPV rule and the total NPV of the portfolio is 424. And the considering the uncertainty embodied in the oil/gas projects and the flexibility, the manager will select projects A, C, D from the portfolio based on Eq.(4),(5),(7)and the total value is 763 (see table 4 ).

Table 4. Results from NPV and real option analysis

\begin{tabular}{|l|l|l|l|l|}
\hline Projects & A & B & C & D \\
\hline NPV (M US\$) & 121 & 145 & 158 & 132 \\
\hline V* $^{*}$ (M US \$) & 253 & 191 & 284 & 226 \\
\hline
\end{tabular}

On the other hand, if these reserves do not reach their respective $\mathrm{V}^{*}$, which would happen because of price reduction or cost increase. In this case, the firm would develop immediately only reserve $\mathrm{C}$, and save a large part of budget to be allocated in more profitable opportunities. Valuable option to wait leads firms to invest only at large positive NPV, the impact of competition drastically erodes the value of the option to wait and leads to investment at very near the NPV threshold. However, this is valid for competitive markets where firms don't have proprietary options, especially in projects of research and development (R\&D), and not for proprietary options as the development of reserves, with embodied geological, operational, and financial uncertainties that enrich the option timing.

\section{Conclusions}

Portfolio selection of oil/ gas projects is a fundamental subject of capital budgeting in the energy sector. In industry, strategic planning requires the selection of a portfolio of projects to advance the corporate goals. In this paper, we discuss the oil/gas projects valuation methods first. Considering the characteristic of the oil/gas project, Real options method is more suitable for the oil/gas project than NPV method, and then a new model extended from the Black-Scholes model is built up. Finally, this paper put forward the portfolio selection model and gives a Computational case.

In this paper, we just discuss the single real option in the oil/gas projects. Actually, the decision-making may be different if option timing is not valuable or easily eroded by competitors. It is difficult if consider the compound option or the role of learning options and synergy between two or more real projects. The impact of sequential investment and active management on the value of a portfolio of real options also will increase the complexity of the problem. In following research, we will continue our research on the portfolio selection of the oil/gas project with compound option or the learning options and synergy between two or more real projects. 


\section{References}

1. Markowitz, H.: Portfolio Selection, J. of Finance, (1952) 77-91.

2. Luehrman, T.A.: Extending the Influence of Real Options: Problems and Opportunities, paper SPE 71407, presented at the 2001 Annual Technical Conference and Exhibition, New Orleans, Louisiana, 2001.

3. Paddock, J., Siegel, D. and Smith, J.: Option Valuation of Claims on Physical Assets: The Case of Offshore Petroleum Leases, Quarterly Journal of Economics, 103 (1988): 479508.

4. Trigeorgis L., Real Options: Managerial Flexibility and Strategy in Resource Allocation, MIT Press Cambridge, Massachusetts. 1996

5. Barone-Adesi G. and Whaley R.E. : Efficient Analytical Approximation of American Option Values, Journal of Finance, (1987)301-320

6. Cox J., S. Ross and M. Rubinstein: Option Pricing: A Simplified Approach, Journal of Financial Economics, (1979)229-263

7. Margrabe, W.: The Value of an Option to Exchange One Asset for Another, Journal of Finance, 33(1978) 177-186.

8. Dixit A.K. and Pindyck R.S. :Investment under Uncertainty, Princeton University Press, Princeton, NJ, 1994

9. Copeland T., Koller T. and Murrin J. Valuation: Measuring and Managing the Value of Companies, John Wiley and Sons, NY, 1990

10. Black F. and M. Scholes: The Pricing of Options and Corporate Liabilities, Journal of Political Economy, (1973)637-659

11. Luehrman, Timothy A.: Capital Projects as Real Options: An Introduction, Harvard Business School Technical Note, 1994

12. Dixit, A. K., R. S. Pindyck. Investment Under Uncertainty. Princeton University Press, Princeton, 1994 